\title{
A History of Diamonds through Philately: The Frank Friedman Collection
}

\author{
Stuart D. Overlin
}

South African jeweler Frank Friedman's collection of diamond-themed stamps and other postal material offers an illuminating visual record of diamond history. Comprising approximately 2,000 pieces, these items chronicle diamond formation, the history of mining and manufacturing, and the evolution of a science and an industry built around this remarkable gemstone.

$\mathrm{P}$ hilately, the collecting of stamps and other postal material, first became popular with the introduction of the British penny and twopenny adhesive stamps in 1840. Much of the hobby's attraction lies in the range of fascinating subjects that have been documented. Diamonds have appeared in postage stamps, special cancellation marks, and postcards issued by numerous countries, especially those with ties to the industry (figure 1). The present article reviews one important collection of such material.

Frank Friedman (figure 2) has spent much of his life in the South African gem and jewelry industry. He joined the family enterprise, J. Friedman Jewellers, as an apprentice goldsmith in 1959 and helped build it into one of the country's top retailers. In 1985 he established F. Friedman Jewellers, which was rebranded as Frankli Wild in 1999.

Mr. Friedman began collecting stamps in 1961, inspired by a jewelry magazine article that described

See end of article for About the Author and Acknowledgments.

Gems \& GemOlogy, Vol. 47, No. 3, pp. 214-219,

http://dx.doi.org/10.5471.GEMS.47.3.214.

(C) 2011 Gemological Institute of America the hobby as "the poor man's way to collect gems" (Friedman, 2007). He joined the Johannesburg Philatelic Society to learn more and began to acquire pieces. His collection now totals approximately 2,000 items from more than 36 countries. In addition to stamps, it contains rare postcards, cancellation marks, historical letters, and original artists' renderings of stamp and cancellation designs.

Mr. Friedman has displayed his collection internationally on several occasions. In 1989 it was showcased in the Harry Oppenheimer Museum at the Israeli Diamond Center in Ramat Gan. In June 1997, it was the keynote exhibit at the Vicenza Trade Fair (Weil, 1997). Awards include a gold medal at the 2006 World Philatelic Exhibition in Washington ("Stamp of approval," 2006), a 2008 silver medal at the World Stamp Championship in Israel, and a large vermeil medal at the 26th Asian International Stamp Exhibition (Joburg 2010).

\section{HIGHLIGHTS FROM THE COLLECTION}

Selected items from the Friedman collection, arranged thematically, are described below. These were chosen for their historical and educational value.

Diamond Origins. The pair of stamps in figure 3 depicts the eruptive emplacement of diamonds on the earth's surface. The 1973 Lesotho stamp provides a cross-section of a diamond-bearing kimberlite pipe. The artist's rendering for a 1993 stamp from the Tongan island of Niuafo' ou shows an erupting volcano juxtaposed with diamond crystals and a polished stone.

History of Prospecting and Mining. Throughout much of recorded history, India was the world's sole diamond source. After alluvial diamonds began to 


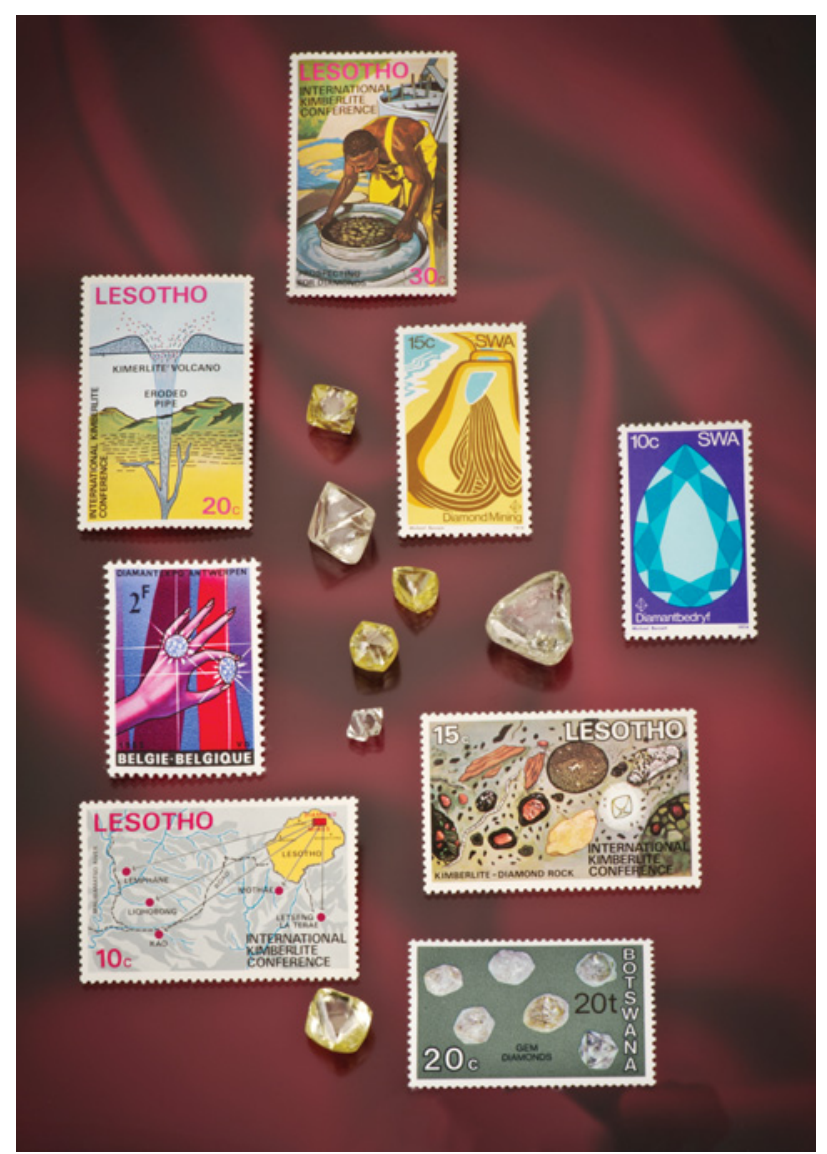

Figure 1. These diamond-themed stamps issued by various countries are shown with seven rough crystals (1.24-22.32 ct). The diamonds were donated to GIA by De Beers chairman Ernest Oppenheimer in 1955. Photo by Robert Weldon.

Figure 2. Jeweler Frank Friedman examines some of the prized stamps from his collection. "Through stamps you learn so much about the different countries and glean a lot of information about the diamond trade in those countries," he says. Photo by Merle Friedman.

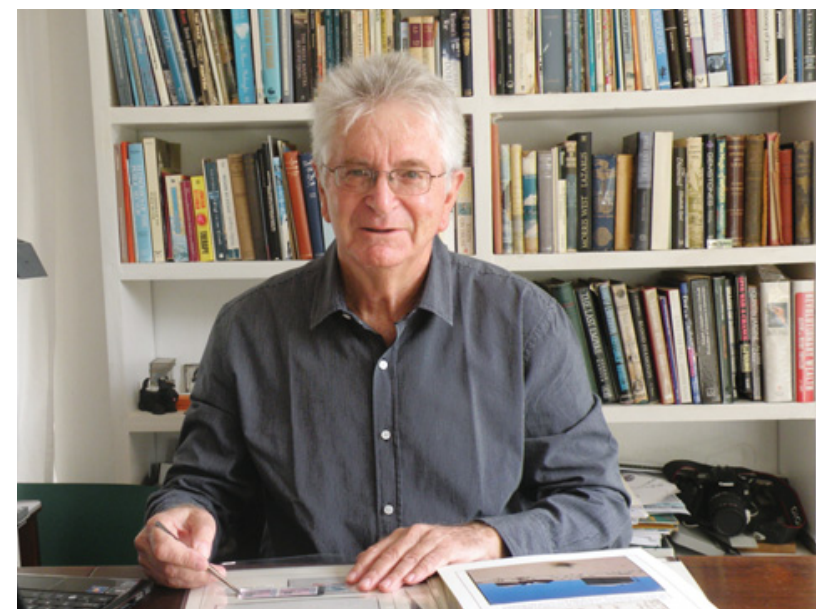

\section{NEED TO KNOW}

- Jeweler Frank Friedman's diamond-themed collection of stamps and other postal material contains $\sim 2,000$ pieces, representing more than 36 countries.

- The pieces date back to the early 19th century and illustrate diamond formation, the growth of the global trade, the cutting and polishing processes, important diamonds, and distinguished scientists.

emerge from Brazil in the mid-1700s, the Portuguese crown controlled the market for the next hundred years. The Friedman collection's earliest cover, an envelope or postcard sent through the mail system, is an 1807 specimen with a postmark from the Brazilian mining town of Diamantina (figure 4).

The discovery of diamonds in South Africa in late 1866 marked the birth of the modern industry. Although the country did not issue stamps featuring diamonds until 1960, other postal items show early South African mining. Examples are an 1873 cover with a "De Beers NR" (New Rush) cancellation mark and turn-of-the-century postcards from the Jagersfontein and Kimberley mines (again, see figure 4).
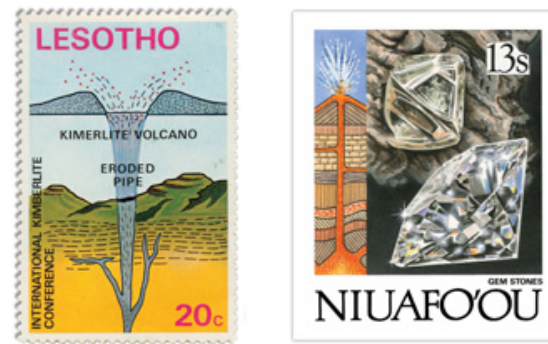

Figure 3. The Lesotho stamp on the left and the artist's rendering for a stamp from the Tongan island of Niuafo'ou illustrate the process of diamond emplacement in kimberlite.

Twentieth-century mining developments elsewhere in Africa are represented in figure 5. In 1964, three decades after it began producing diamonds, Sierra Leone issued the world's first self-adhesive stamps, bearing the inscription "Land of Iron \& Diamonds." Subsequent stamps featuring diamonds 


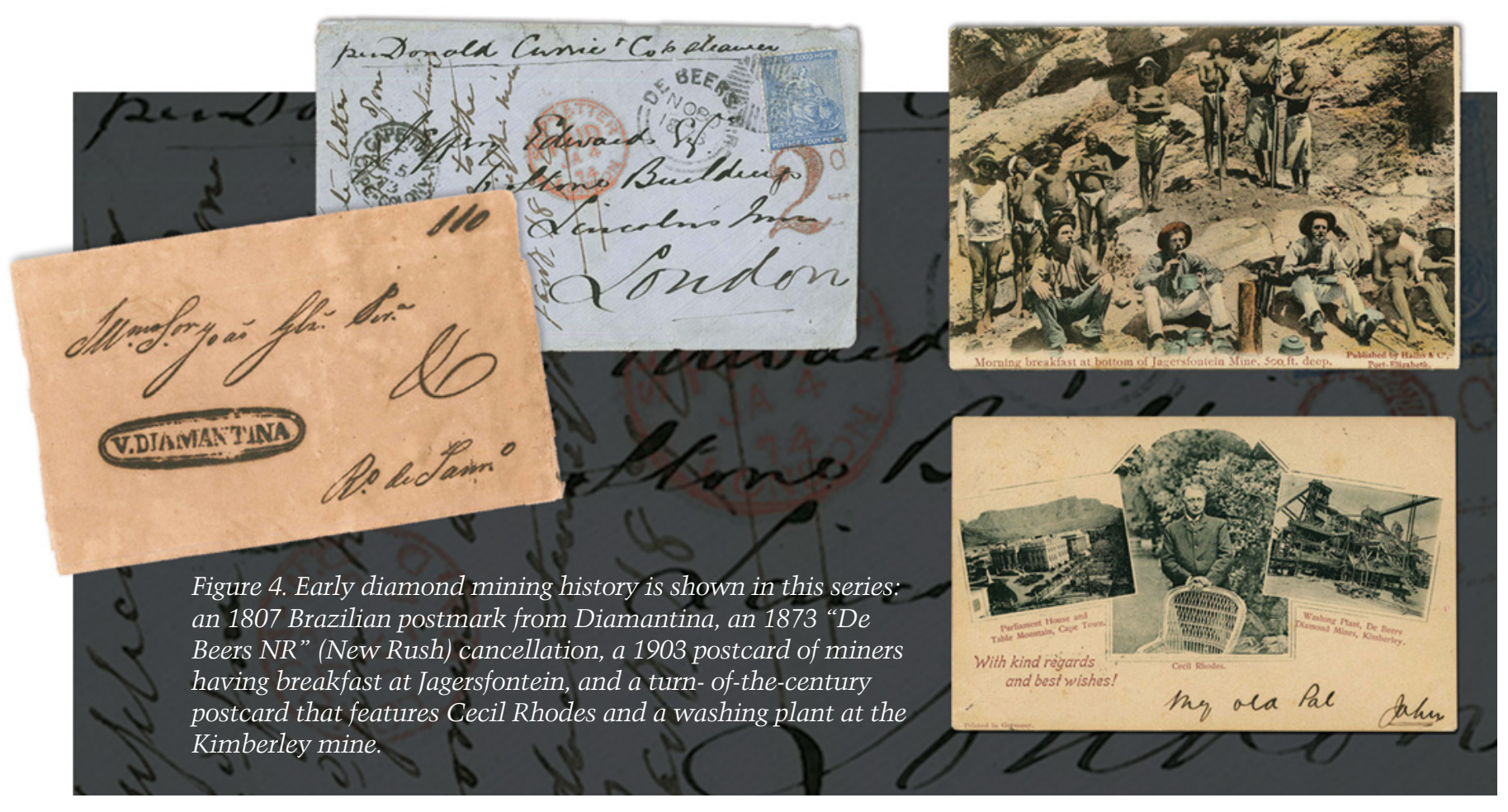

had advertisements for Harry Winston on the paper backing. Other pieces from this set recognize diamond mining in South-West Africa (now Namibia). An original artist's rendering for a 1974 stamp shows marine mining along the coastline, while a 1983 issue marks the 75th anniversary of Namibian diamond mining. In the latter scene, prospectors are literally scratching the surface of the desert at Kolmanskop (near Lüderitz). A 1987 stamp shows Kolmanskop after it was abandoned in 1950, while a 2008 set of four commemorates the country's diamond mining centennial.

The Global Diamond Industry. Pioneers of the African diamond industry appear in figure 6, beginning with a 1940 stamp from Southern Rhodesia (now Zimbabwe) bearing a likeness of De Beers founder Cecil Rhodes (1853-1902). A 75th anniversary stamp commemorates August Stauch, the railroad supervisor who secured the prospecting rights near Lüderitz in 1908 after his employees brought

Figure 5. Items related to 20th century diamond mining include (clockwise from top left) a diamond-shaped stamp and a Harry Winston advertisement from the backing of a self-adhesive stamp, both from Sierra Leone; an original rendering of coastal mining in SouthWest Africa; four stamps marking the 100th anniversary of diamond mining in South-West Africa (now Namibia); and a pair of stamps showing the desert mining town of Kolmanskop.

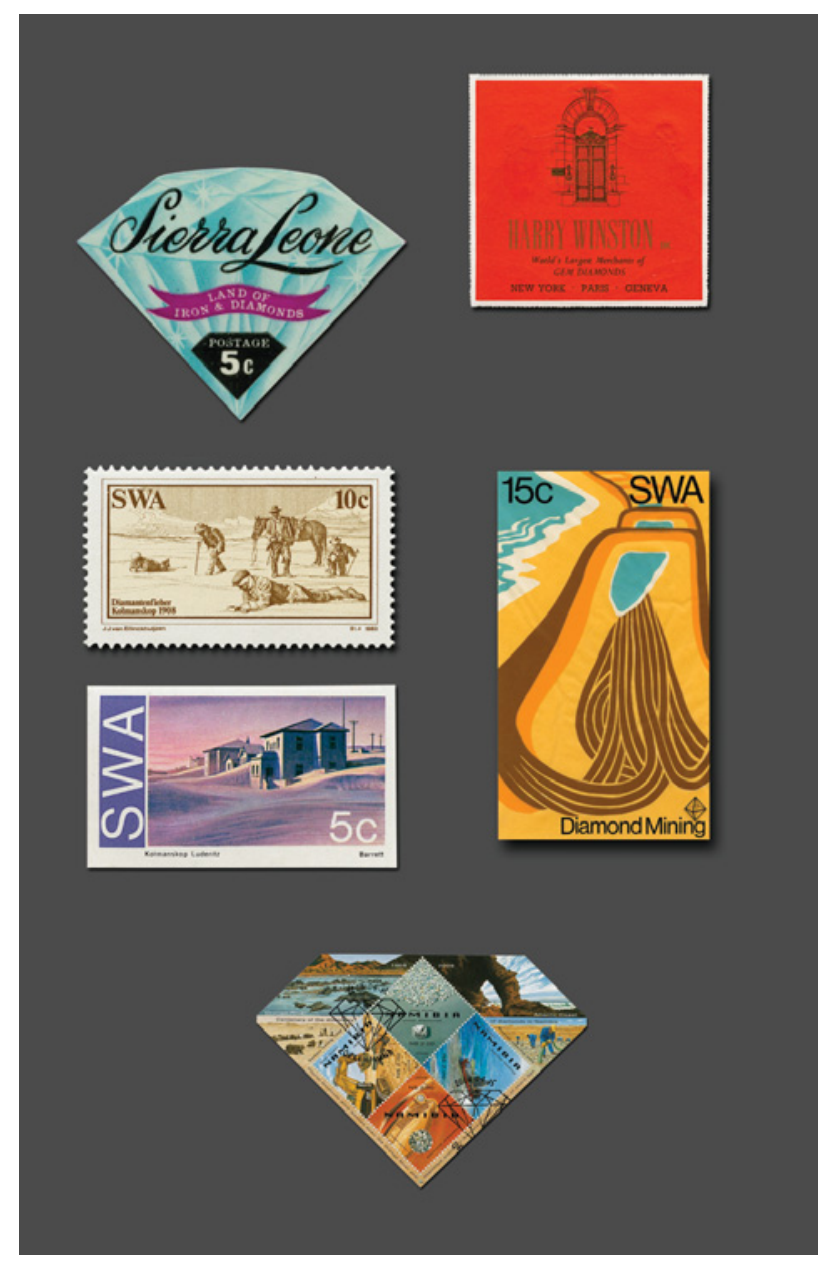




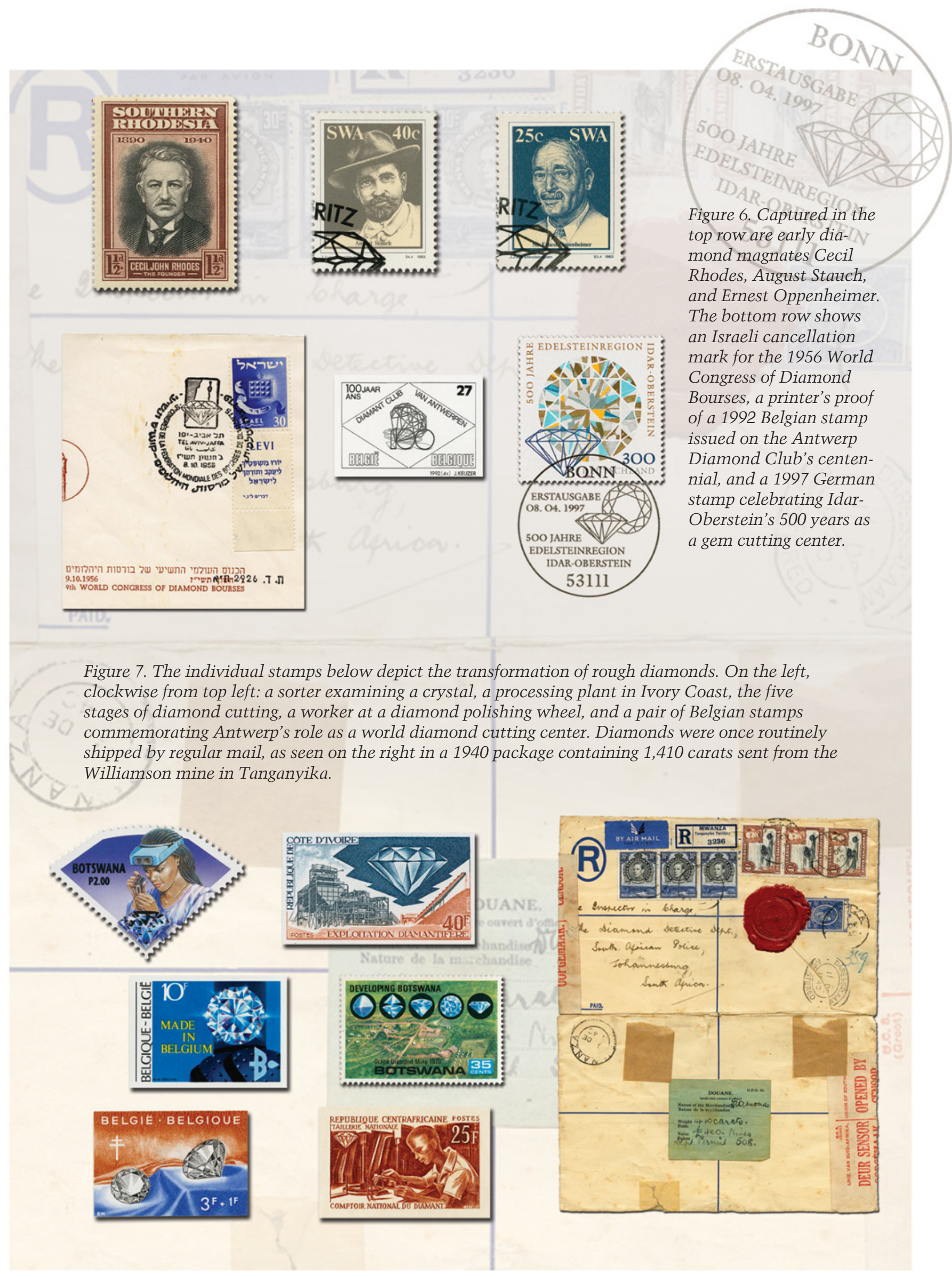




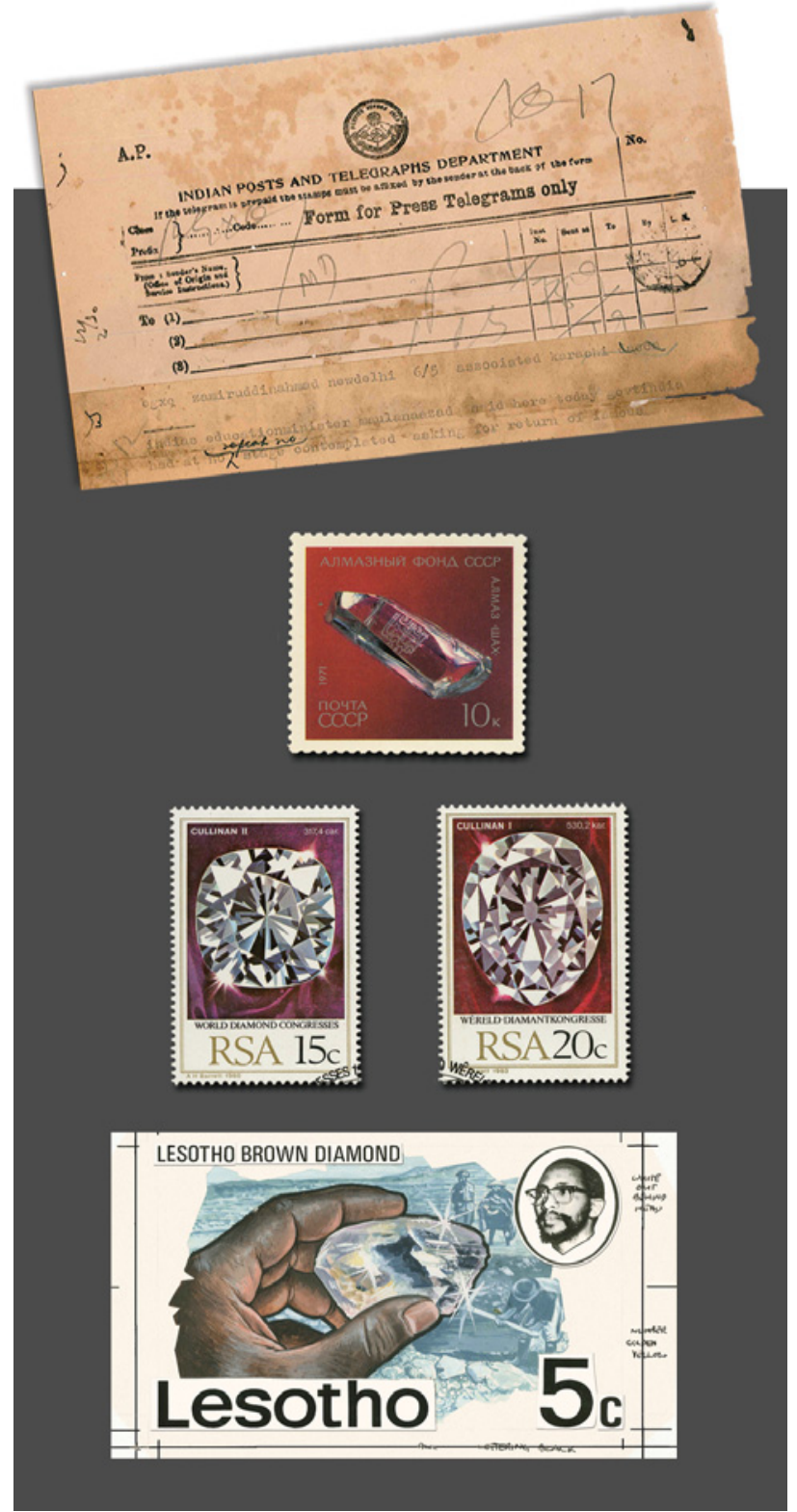

Figure 8. Famous diamonds appear in these items from the Friedman collection (top to bottom): a 1953 telegram from the Indian parliament regarding ownership of the Koh-i-Noor, a 1971 Soviet stamp depicting the Shah diamond, South African stamps of Cullinans I and II, and an original artist's rendering for a 1976 stamp of the Lesotho Brown.

him handfuls of shiny stones. A 1983 stamp from South-West Africa honors Sir Ernest Oppenheimer (1880-1957), who led De Beers for 30 years and established its Central Selling Organisation in 1934.

The collection also offers a glimpse into the diamond trade's impact elsewhere. These pieces include an Israeli cancellation mark created for Tel Aviv's hosting of the 1956 World Congress of Diamond Bourses, a 1992 Belgian stamp printed for the Antwerp Diamond Club's centennial, and a 1997 German stamp celebrating 500 years of the diamond and colored stone industry in Idar-Oberstein.

Cutting and Polishing. Figure 7 follows the transformation of diamonds from rough to polished gems, starting with a signed proof of a 1972 Ivory Coast stamp of a diamond processing plant. In a 2001 stamp issued by Botswana, a sorter uses her loupe visor to examine a crystal. A printer's proof of an Ivory Coast stamp from 1972 shows a processing plant, while a 1970 Botswanan stamp illustrates the five stages of diamond cutting: rough octahedron, sawn crystal, fashioned girdle, polished top, and brilliant cut. A signed proof of a 1966 Central African Republic stamp shows a worker at a polishing wheel. Belgian-issued stamps from 1960 and 1983 celebrate Antwerp's role as a world diamond cutting center. Diamonds all along the distribution chain were once routinely shipped by regular mail, as indicated by the parcel carrying 1,410 carats of diamonds from the Williamson mine in Tanganyika (now Tanzania) in 1940, the year it opened.

Famous Diamonds. The Friedman collection also portrays some of the world's most exceptional diamonds (figure 8). The first is the legendary Koh-iNoor, the ancient Indian diamond that was handed over to the British Empire in 1850. Evidence of a postcolonial dispute over the Koh-i-Noor emerges in a 1953 telegram from the Indian parliament that mentions the diamond's ownership. A 1971 Soviet stamp shows the 88.7 ct table-cut Shah, including the engraved inscriptions. This diamond was offered by Persian ruler Fath Ali Shah to placate Czar Nicholas I after the 1829 assassination of a Russian diplomat (Balfour, 2000). Cullinans I and II, cut from a 3,106 ct piece of rough discovered at South Africa's Premier mine, became the centerpiece of the Crown Jewels of England. They are seen in a pair of 1980 South African stamps issued on the 75th anniversary of the discovery of the rough. Rounding out this group is a hand-painted proof of a 1976 stamp featuring the Lesotho Brown. This $603.1 \mathrm{ct}$ diamond was discovered in 1967 and later cut into 18 stones, one of which was set in an engagement ring for Jacqueline Kennedy Onassis (Balfour, 2000).

Scientific Breakthroughs. Figure 9 shows a selection of stamps commemorating scientists who advanced our understanding of diamonds. A 1980 German stamp recognizes naturalist Albertus Magnus 


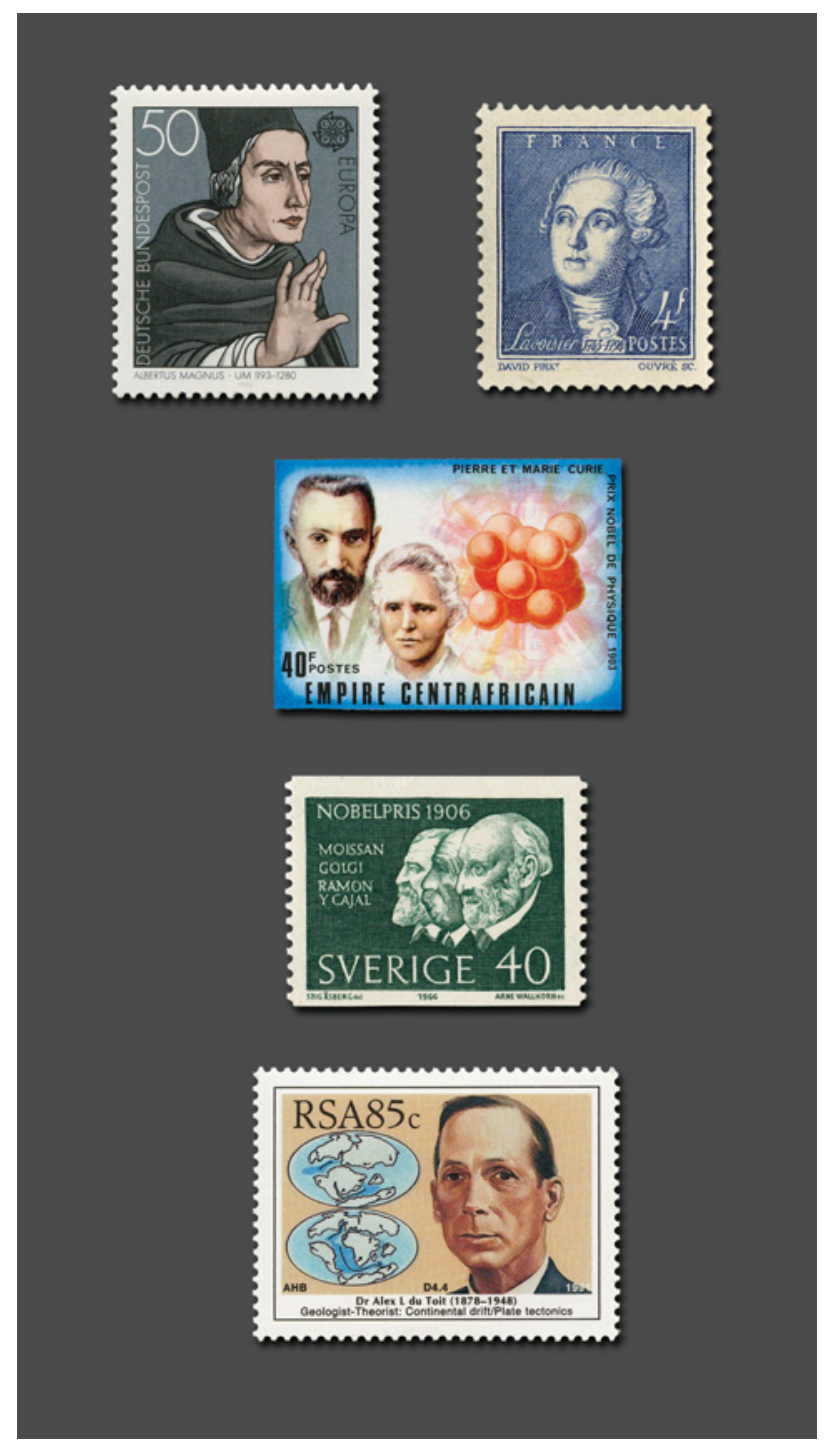

Figure 9. These stamps featuring Albertus Magnus, Antoine Lavoisier, Pierre and Marie Curie, Henri Moissan (far left in the group illustration), and Alexander Du Toit recognize pioneers of diamond research.

(1193-1280), a medieval writer on diamonds and one of the first to document the gem's extraordinary hardness. The famed chemist Antoine Lavoisier (1743-1794), whose research demonstrated that diamond consists of pure carbon, is featured in a 1943 French stamp. A 1977 stamp issued by the Central African Republic pays tribute to Marie and Pierre Curie, who received the 1903 Nobel Prize in physics for their early studies of radiation and tested its effects on diamond. Fellow Nobel Prize winner Henri Moissan, seen in a 1966 Swedish stamp, per- formed early experiments on diamond synthesis. In 1991, South Africa issued a stamp in honor of Alexander Du Toit, the chief geological consultant to De Beers from 1927 to 1941. Dr. Du Toit mapped the geology of his native country and produced influential work supporting the continental drift theory, which asserts that South Africa and South America were once connected.

\section{CONCLUSION}

Fifty years after starting his collection, Mr. Friedman still adds to it regularly. "One of the thrills of collecting is filling that gap that has eluded me for years, or finding an unusual variety in an unexpected way," he says. "For instance, I've just acquired a Namibian stamp of a diamond-barren kimberlite pipe. It enhances the Namibian content."

Even in the age of digital communication, philately remains a powerful educational medium, a form of visual history in miniature. The portraits, scenes, and other information capture illuminating details and foster greater appreciation of the subject. Frank Friedman's philatelic collection, which preserves several aspects of diamond history, represents an important contribution to gemology's scholarship and heritage.

\section{ABOUT THE AUTHOR}

Mr. Overlin is associate editor of Gems \& Gemology.

\section{ACKNOWLEDGMENTS}

The author gratefully acknowledges the research assistance of Kathleen Dailey, Gus Pritchett, and Rose Tozer of GIA's Richard T. Liddicoat Library and Information Center in Carlsbad. GIA's McKenzie Santimer and Lynn Viall provided diamonds for photography.

\section{REFERENCES}

Balfour I. (2000) Famous Diamonds, 4th ed. Christie, Manson and Woods Ltd., London, $320 \mathrm{pp}$.

Friedman F. (2007) Diamonds and philately. The SA Philatelist, April, pp. 263-264.

Stamp of approval (2006) SA Jewellery News, August, p. 55.

Weil A. (1997) Keystone exhibit honours SA jeweler. Diamond News ↔) SA leweller, August, p. 11. 